\title{
Deposition, morphology and functional properties of layers based on DLC:Si and DLC:N on polyurethane
}

\author{
Karol Kyzioł ${ }^{1}$ (D) Piotr Jabłoński ${ }^{1} \cdot$ Wiktor Niemiec $^{1} \cdot$ Janusz Prażuch $^{1} \cdot$ Daniel Kottfer $^{2} \cdot$ Aneta Łętocha $^{3}$. \\ Łukasz Kaczmarek ${ }^{4}$
}

Received: 7 April 2020 / Accepted: 21 August 2020 / Published online: 31 August 2020

(c) The Author(s) 2020

\begin{abstract}
DLC:Si and DLC:N (diamond-like carbons doped with Si or N) functional layers in different configurations are deposited on polyurethane (PU) for bioengineering applications using CCP (capacitively coupled plasma) discharge generated in the PE CVD (plasma-enhanced chemical vapor deposition) system. Scanning electron microscopy (SEM) observations show that the obtained single and multilayers are continuous and well adherent to the substrates, but they differ in surface morphologies. DLC:Si layers form granular-like outer surfaces, while DLC:N ones a mosaic structure of plain areas. Topography analyses by atomic force microscopy (AFM) and optical profilometry reveal that Si-doped layers are characterized by significantly higher surface roughness $\left(R_{\mathrm{a}}\right.$ ca. $\left.5 \mathrm{~nm}\right)$ in comparison to $\mathrm{N}$-doped layers $\left(R_{\mathrm{a}}\right.$ ca. $\left.0.3 \mathrm{~nm}\right)$ and also higher values of profile roughness parameter $\mathrm{R}_{\mathrm{z}}$ (up to $32 \mu \mathrm{m}$ vs. about $13 \mu \mathrm{m}$ ). Energy-dispersive X-ray spectroscopy (EDS) analysis indicates the homogenous chemical composition of the layers. DLC:N layers, are characterized by significantly higher polar component of surface free energy (up to ca. $5.0 \mathrm{~mJ} / \mathrm{m}^{2}$ ). DLC:Si layers exhibit higher values of diiodomethane contact angle (up to ca. $90^{\circ}$ ) compared with DLC:N layers (up to ca. $55^{\circ}$ ). The attenuated total reflectance Fourier transform infrared spectroscopic measurements (ATR-FTIR) of the layers reveal that the addition of silicon to the DLC structure increases the content of terminal $\mathrm{CH}_{\mathrm{n}}$ bonds $(n=1,2,3)$ as well as beneficial $\mathrm{Si}-\mathrm{H}$ and $\mathrm{Si}-\mathrm{CH}_{\mathrm{n}}$ bonds, which significantly reduce the internal stresses in the layers. Both DLC:Si and DLC:N layers exhibit no cytotoxic effects using the human osteoblast-like cell line and human keratinocytes.
\end{abstract}

Keywords Polyurethane $\cdot$ DLC-based coatings $\cdot$ RF CVD $\cdot$ Surface roughness $\cdot$ Biocompatibility

\section{Introduction}

Polymers are an interesting group of engineering materials, which, due to their attractive properties, for example a quite good chemical resistance, low weight as well as

Karol Kyzioł

kyziol@agh.edu.pl

1 Faculty of Materials Science and Ceramics, AGH University of Science and Technology, A. Mickiewicza Av. 30, 30059 Kraków, Poland

2 Faculty of Mechanical Engineering, Department of Technologies and Materials, Technical University in Kosice, Masiarska 74, 04001 Kosice, Slovakia

3 Łukasiewicz Research Network - Krakow Institute of Technology, Zakopianska Str. 73, 30418 Kraków, Poland

4 Institute of Materials Science and Engineering, Łódz University of Technology, Stefanowskiego Str. 1/15, 90924 Łódz, Poland biocompatibility, are used in tissue engineering and regenerative medicine [1]. This group includes, among others, polyethylene (PE), polyetheretherketone (PEEK), polycaprolactone (PCL) and polyurethane (PU). Despite the numerous advantages of polymers, there is a need to improve their useful parameters (e.g., surface hardness, tribological properties, biocompatibility, antibacterial activity), which can be achieved by modifying their surface [2]. Therefore, special surface treatment methods are widely used to enhance cell compatibility and promote cell proliferation as well as to improve the physicochemical properties of PUs. These technologies are often based on plasma discharge, deposition of functional layers, and other chemical reactions and processes under low pressure (vacuum) conditions [3, 4].

The application of the plasma treatment or plasma chemical processes leads to generating high-energy species, such as radicals, ions or molecules, which (depending on the chemical composition) involves surface reactions, surface activation and modification. These processes can modify 
polymeric material, including polyurethane, to obtain biomedical material, for example they can lead to obtaining functional layers based on the DLC (Diamond-like Carbon) structure [5]. Fundamental study on polymer surface modifications using plasma processes was performed by Friedrich et al. [6], Mwale et al. [7], Ohl et al. [8], Oehr [9], Martinu et al. [10] and Yasuda [11].

DLC layers have wide-ranging properties, such as lowto-high hardness, smooth surface morphology, low friction coefficient, chemical inertness, wear resistance and biocompatibility. Various DLC structures are characterized by different relations of $\mathrm{sp}^{3}$ and $\mathrm{sp}^{2}$ bonds, which provide specific properties of this type of layers $[12,13]$. The relatively high content of $\mathrm{sp}^{3}$ carbon hybridization guarantee very good mechanical properties, Young's modulus around $300 \mathrm{GPa}$, a hardness over $17 \mathrm{GPa}$ and a coefficient of friction below 0.05 . In the case of DLC coated polymer substrates, their mechanical and tribological properties are very difficult to evaluate due to the effect of the substrate. The physical and mechanical properties of the modified surface depend on the type of substrate, deposition method, the thickness of the layer as well as the precursors used, etc.[14]. For example, the hardness values of DLC deposited on the elastomer is ca. $0.1 \mathrm{GPa}$, whereas that deposited on the Si substrate is in the range of 6-17 GPa [15]. Lackner et al. reported that DLCs deposited on thermoplastic polyurethanes are characterized by hardness values in the range of 0.1-5.0 GPa, depending on the used gas mixture as well as the pressure in the reactor [16]. Due to the high hardness of DLC layers, such coatings are commonly used in implantology, especially in hip joint implants $[17,18]$.

Futhermore, a DLC structure can be modified using different atoms in the plasma process, i.e., $\mathrm{Si}, \mathrm{N}, \mathrm{Ag}, \mathrm{O}$ or Ti. Some of them impart antibacterial properties, e.g., the addition of silicon (DLC:Si) above a concentration of $16 \%$ at. $[19,20]$. For instance, the research conducted by Hauert et al. confirmed that $21 \%$ at. content of silicon in the resulting structure ensured good antibacterial effects [21]. Importantly, some studies [22, 23] indicate that the presence of atomic groups in DLC structures containing $\mathrm{Si}$ and/or N atoms leads to internal stress reduction. In addition, such DLC layers should be characterized by the simultaneous non-cytotoxic effect allowing for the biological applications.

DLC layers on a PU substrate were obtained by the PE CVD method, inter alia, by Matsumoto et al. [5]. The resulting structures were characterized by poor adhesion strength; however, is was demonstrated that PU pre-treating in an oxygen plasma can significantly improve adhesiveness. At the same time, these layers did not show any cytotoxicity. In turn, the study conducted by Morozov et al. [24] proved that the surface activation of the polyurethane in the nitrogen plasma created the conditions for the growth of the carbon coating (using pulsed magnetron sputtering of a graphite target) in the form of separate islets. The diameter and height of the latter depended on the technological parameters and increased from ca. $1 \mu \mathrm{m}$ and ca. $10 \mathrm{~nm}$, respectively. Thus, the treatment resulted in a granular structure and an increase in roughness. These types of layers were characterized by good adhesion to the PU substrate, and in this case with the processing time, the surfaces became more homogeneous. Generally, the current state of art indicates that adhesion of DLC layers to polymeric materials is quite weak. Therefore, it is necessary to improve the adhesion strength between the layers and polymeric substrates. This can be achieved by argon and/or oxygen plasma treatment of a polymer surface or by inter-layer deposition [5]. To obtain well adherent DLC layers to the PU substrates, a novel technological solution is based on the deposition of DLC:Si and DLC:N multilayers taking advantage of individual properties of each layer. It is assumed that the presence of Si in the DLC structure favors a stronger bonding between the PU surface and DLC layer due to chemical interaction. Such surface layers should be more resistant to delamination and external deformation. The physicochemical and biological properties of the resulting materials make them suitable for bioengineering applications. As well, the addition of $\mathrm{N}$ and $\mathrm{Si}$ atoms to the diamond-like carbon structure is beneficial, because it leads to a decrease in the value of internal stresses inside the obtained coatings as well as in their hardness. This was observed by Ray et al. [22] and Sharifahmadian et al. [25].

In this paper, the PE RF CVD (plasma-enhanced radio frequency chemical vapor deposition) method using a capacitively coupled plasma (CCP) was applied to modify the surfaces of the polyurethane substrates. The processes carried out under plasma chemical conditions included an etching of PU surface using $\mathrm{Ar}^{+}$ions, and obtaining (in the next stage) DLC layers doped with $\mathrm{Si}$ or $\mathrm{N}$ atoms, in various configurations. The pretreatment based on $\mathrm{Ar}^{+}$ plasma etching was used to obtain not only the appropriate roughness of the polyurethane surface, but such treatment can also guarantee antibacterial properties and blood compatibility, as proved by Alves et al. [26]. In this work we also applied the etching process with the application of argon ions to activate the PU surface by purification and removal of contamination (chemical and biological) as well as to increase surface roughness to improve adhesion of the deposited layers.

Unmodified and modified PU substrates were precisely characterized by scanning electron microscopy (SEM), energy-dispersive spectroscopy (EDS), atomic force microscopy (AFM) and optical methods as well as infrared spectroscopy (IR) to investigate the atomic structure of the obtained coatings. Additionally, the contact angle and surface free energy (SFE) of the tested samples were examined. The biological activity in vitro against the MG-63 and $\mathrm{HaCaT}$ cell line was evaluated by the Alamar Blue assay. 


\section{Materials and methods}

\subsection{Samples preparation and surface treatment}

The polyurethane substrates (Sigma-Aldrich) used in this study were prepared as regular shaped samples (width/ length/height $-5 / 10 / 5, \mathrm{~mm}$ ). According to the EDS analysis, the average chemical composition of this material was 84.2 at. \% carbon, 13.6 at. $\%$ oxygen and 2.2 at. $\%$ nitrogen. Before the plasma modification, the PU samples were polished using $\mathrm{SiC}$ grinding papers of various gradations, in succession \#320, \#800 and \#1000 $\mu \mathrm{m}$, with water cooling. Subsequently, the polymeric substrates were chemically purified using an ultrasonic bath (Fisher Scientific) in isopropanol $\left(\mathrm{C}_{3} \mathrm{H}_{8} \mathrm{O}\right.$, p.a.) for $15 \mathrm{~min}$. Surface modification of PU substrates was carried out with the application of the PE RF CVD system (Elettrorava S.p.A., Italy), using a capacitively coupled plasma (radio-frequency discharge of $13.56 \mathrm{MHz}$, $300 \mathrm{~W}$ ). All plasma processes (plasma etching and layers deposition) on PU substrates were performed without substrate heating due to the relatively low thermal resistance of polyurethane. The plasma was generated between two electrodes (cathode-anode as parallel plates) at a distance of $20 \mathrm{~mm}$; see Fig. 1 .

Plasma chemical processes in the RF reactor, for the given technological conditions during layers deposition, increased both electrodes temperatures up to ca. $45^{\circ} \mathrm{C}$. The plasma etching process was applied using $\mathrm{Ar}^{+}$ions at an argon flow rate of $75 \mathrm{~cm}^{3} / \mathrm{min}$, a pressure in the chamber of $53 \mathrm{~Pa}$ and 10-min times for each of the modified series. The etching process was carried out with the power of $8 \mathrm{~W}$ plasma to minimize the negative influence of the temperature increase on the PU surface, which causes surface degradation. This process was supposed to remove possible adsorbed gases (e.g., oxygen) from the surface and activate the substrate before the processes of obtaining layers.

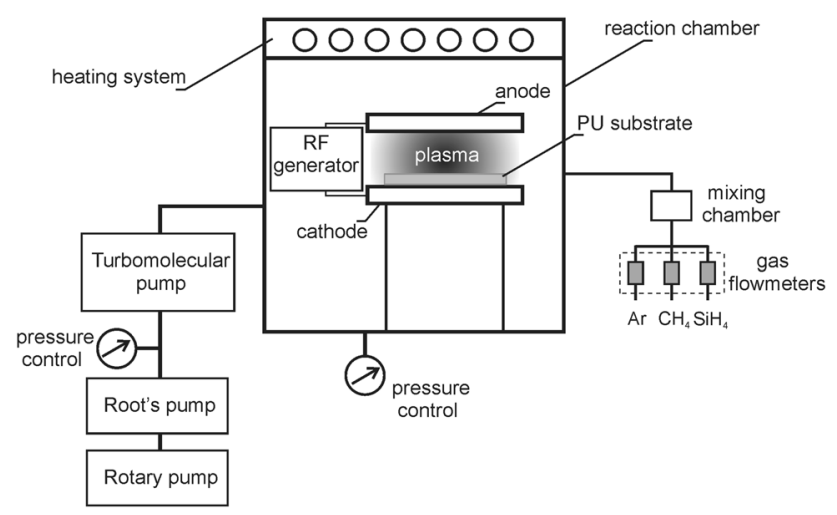

Fig. 1 Scheme of the RF CVD system used for surface modification of PU substrates
In the conducted research, after plasma etching of PU substrates, five independent depositions $\left(\mathbf{J} \_\mathbf{1}-\mathbf{J} \_\mathbf{5}\right)$ of DLC:N and/or DLC:Si layers on the substrate surface were carried out for $30 \mathrm{~min}$ in the case of each layer. The first three series $\left(\mathbf{J} \_\mathbf{1}-\mathbf{J} \_\mathbf{3}\right)$ included the preparation of singlelayer coatings: 1) DLC:Si (J_1), 2) DLC:N with different content of $\mathrm{N}_{2}$ in the gas mixture $\left(\mathbf{J} \_\mathbf{2}, \mathbf{J} \_\mathbf{3}\right)$. In the case of Si-doped DLC layers, the reaction mixture included methane $\left(\mathrm{CH}_{4}, 8 \mathrm{sccm}\right.$ flow, purity $\left.99.9995 \%\right)$, silane $\left(\mathrm{SiH}_{4}, 8 \mathrm{sccm}\right.$ flow, purity $99.9999 \%$ ), and argon (Ar, $80 \mathrm{sccm}$ flow, purity 99.999\%) as working gas. For N-doped DLC layers, the process was carried out in the $\mathrm{N}_{2} / \mathrm{CH}_{4} / \mathrm{Ar}$ atmosphere, for gas flow values of 80/8/8 (in sccm) for $\mathbf{J} \_2$ series and 80/10/10 (in sccm) for $\mathbf{J} \_\mathbf{3}$ series, respectively. Samples of series $\mathbf{J} \_\mathbf{4}$ and $\mathbf{J} \mathbf{5}$ were double layer built of an inner and an outer layer. In the case of series $\mathbf{J} \_\mathbf{4}$, the inner layer was DLC:N and the outer layer was DLC:Si, while in series $\mathbf{J} \_\mathbf{5}$ the inner layer was DLC:Si and the outer layer was DLC:N. In the case of double-layer coatings ( $\mathbf{J} \_\mathbf{4}$ and $\mathbf{J} \_\mathbf{5}$ ), the parameters of the technological conditions for obtaining layers were based on those for the series $\mathbf{J} \_\mathbf{1}$ and $\mathbf{J} \_\mathbf{2}$.

The layers deposition for all the experimental series was carried out under a pressure of the gas mixture in the chamber of $80 \mathrm{~Pa}$ and RF power density of $0.5 \mathrm{~W} / \mathrm{cm}^{2}$. In addition, the unmodified reference series ( $\mathbf{J} \_\mathbf{0}$, after etching in argon plasma) was examined to evaluate the influence of the applied types of surface modifications on the selected physicochemical and biological properties of polyurethane.

\subsection{Surface characterization}

The microstructure and chemical composition of the tested samples were investigated using scanning electron microscopy (NOVA NANO SEM 200, FEI, USA) with energydispersive X-ray (EDX) spectrometry analysis. When light elements (i.e., $\mathrm{C}, \mathrm{N}$ and $\mathrm{O}$ ) were detected, the accelerating voltage value of $5 \mathrm{kV}$ was applied. The thickness of the obtained layers was determined on cross sections of the tested samples during SEM observation. Furthermore, the surface topography was investigated using a Bruker MultiMode VIII atomic force microscope working in the Tapping Mode (semicontact mode) and equipped with antimonydoped silicon tips with nominal radii of $8 \mathrm{~nm}$ and cantilevers with a nominal spring constant of $40 \mathrm{~N} / \mathrm{m}$ and the resonance frequency of $300 \mathrm{kHz}$. Additionally, to quantify the roughness of the tested samples, their surface profiles were carried out using an optical profilometer (confocal profilometry, AltiSurf520, Altimet). FTIR-ATR (Fourier transform infrared-attenuated total reflectance) spectroscopy on a Bio-Rad FTS60 V device (USA) was applied to examine the chemical structure of the polymer surface. The spectra were measured within $400 \div 4000 \mathrm{~cm}^{-1}, 275$ scans and resolutions of $4 \mathrm{~cm}^{-1}$. 
The contact angle and surface energy measurements were calculated using the sessile drop technique performed on a DSA10Mk2 (Kruss) analyzer. The wettability and surface energy measurements were analyzed using ultrahigh-quality water (UHQ - water produced with the use of UHQ-PS, Elga, UK) and diiodomethane (Aldrich, Germany) droplets with a volume of $0.2 \mu \mathrm{l}$. The SFE values were calculated using the Owens-Wendt theoretical model. The parameters were carried out in five independent measurements for each of the tested samples.

\subsection{Cytotoxicity}

The human osteoblast-like MG-63 cell line (ATCC: CRL$1427^{\mathrm{TM}}$ ) and human keratinocytes HaCaT (ATCC: PCS200-011 ${ }^{\mathrm{TM}}$ ) were cultured in Dulbecco's modified Eagle's medium (DMEM) (Immuniq, Poland) with phenol red and supplemented with $10 \%$ fetal bovine serum (FBS) and $1 \%$ of streptomycin/penicillin (Gibco-BRL, Life Technologies, Germany). Both cell lines were incubated at a constant temperature of $37^{\circ} \mathrm{C}$ incubator with a humidified atmosphere of $5 \% \mathrm{CO}_{2}$.

The cytotoxic effect of PU substrates, both the unmodified one and those after the deposition of DLC:N and/or DLC:Si layers on MG-63 and HaCaT cells, was performed using the colorimetric test of viability (Alamar Blue assay) as described above [27]. Briefly, the cells were seeded at a density of $50 \times 10^{4}$ cells suspended in $1 \mathrm{ml}$ of culture media onto each of the samples placed inside 24-well microplates. All samples were previously sterilized under UV radiation for $30 \mathrm{~min}$. The culture plates were cultured in a $37^{\circ} \mathrm{C}$ incubator for $72 \mathrm{~h}$. Every $24 \mathrm{~h}$ the medium was changed for a fresh one. After $72 \mathrm{~h}$ the cells were washed with PBS and incubated with a resazurin sodium salt solution $(25 \mu \mathrm{M}$ in PBS) for $4 \mathrm{~h}$ at $37{ }^{\circ} \mathrm{C}$ in the dark. The fluorescence, associated with the cellular metabolic activity, was measured at
$605 \mathrm{~nm}$ (excitation wavelength $560 \mathrm{~nm}$ ) with a multimode microplate reader (Infinite 200 M PRO NanoQuant, Tecan, Switzerland). The cytotoxicity was given as a percentage of the viable cells treated with the coated polyethylene samples relative to the untreated control cells.

In addition, the cell morphology was visualized with a fluorescence microscope (Olympus IX51, Japan) with an excitation filter of $470 / 20 \mathrm{~nm}$. The cells were stained with fluorescein diacetate (viable cells) and propidium iodide (dead cells). At least five viewing fields containing ca. 100 cells each were analyzed. The images of the tested cells after the treatment with the investigated samples were taken using an inverted microscope equipped with a reflected fluorescence system (Olympus IX51, Japan).

\section{Results and discussion}

The aim of this work was to deposit DLC:Si and/or DLC:N single and double mixed functional layers on plasma-etched PU substrates and evaluate the surface morphology, topography, chemistry and wettability, as well as biocompatibility of the resulting layers.

\subsection{Morphology and topography analyses}

The SEM images of outer surfaces of the studied materials are shown in Fig. 2. The analysis of samples $\mathbf{J} \_\mathbf{1}-\mathbf{J} \_5$ revealed that the deposited layers were continuous, well adherent to the substrates and exhibited different surface morphologies depending on the type of modification. The DLC:Si layers formed granular-like outer surfaces, while the DLC:N ones mosaic structures of plain areas, clearly visible in the case of layers deposited on PUs. In these cases, the DLC:N layers reflected the morphological features of the substrate surfaces. However, in the case of J_5
Fig. 2 The SEM images of the studied PU surfaces: J_0 unmodified, J_1 after DLC:Si deposition $\left(\mathrm{SiH}_{4} /\right.$ $\left.\mathrm{CH}_{4} / \mathrm{Ar}=1 / 1 / 10\right), \mathbf{J} \_2$ after DLC: $\mathrm{N}$ deposition $\left(\mathrm{N}_{2} / \mathrm{CH}_{4} /\right.$ $\mathrm{Ar}=10 / 1 / 1), \mathbf{J} 3$ after DLC:N deposition $\left(\mathrm{N}_{2} / \mathrm{CH}_{4} / \mathrm{Ar}=8 / 1 / 1\right)$, J 4 after DLC:N and DLC:Si deposition, J_5 after DLC:Si and DLC:N deposition
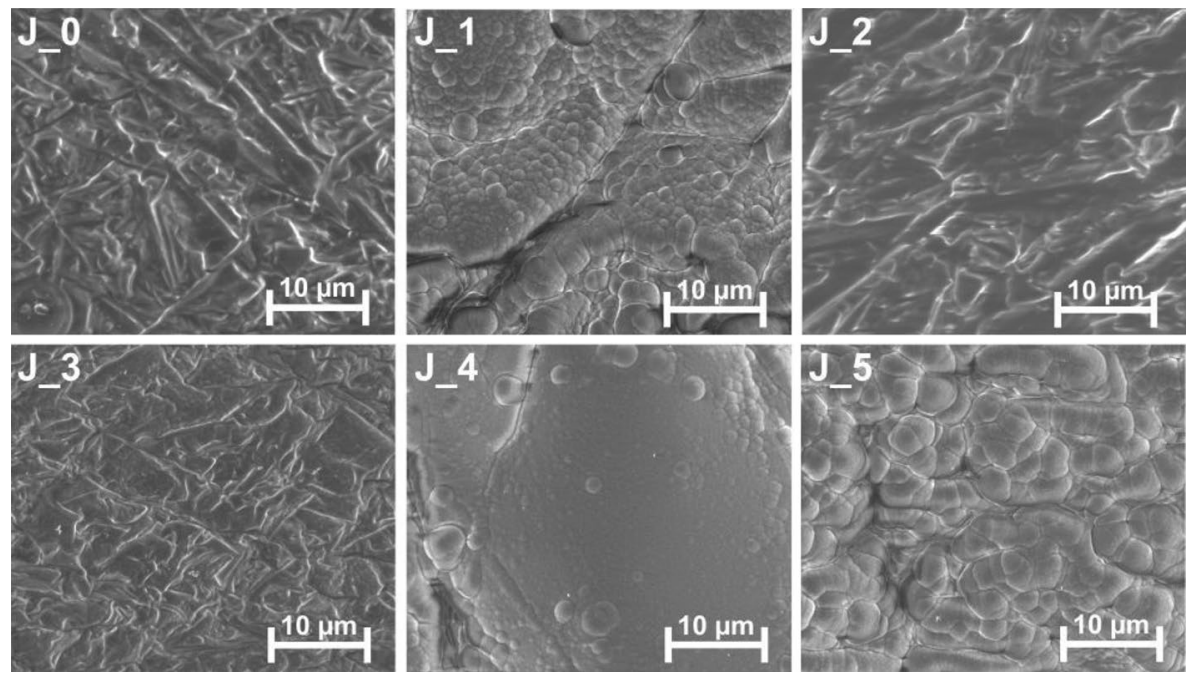
series, the outer DLC:N layer due to its quite slow growth exhibited morphological surface features of the underlying DLC:Si layer. In sample $\mathbf{J} \_\mathbf{4}$, after deposition of the nitrogen-doped DLC layer and the silicon-doped DLC layer, a higher smoothness of the surfaces in the microscale was observed. The thin inter-layers, such as DLC:N, are capable of efficiently improving temperature durability during further processes as well as the deposition of the next layer (in this case of DLC:Si) in the RF reactor, even for substrates showing high thermal expansion [28]. This fact presumably corresponds to the observed results of a distinctly smoother polyurethane surface after plasma modification (the $\mathbf{J} \_\mathbf{4}$ series) in the micrometer scale compared to the $\mathbf{J} \_\mathbf{5}$ series, without a DLC:N interlayer.

Interestingly, analysis of the surface of the samples using atomic force microscopy revealed the nanometric scale of the resulting structures (Fig. 3).

In detail, the AFM images of the modified substrates showed granular-like structures, which in the case of the DLC:Si coatings are composed of agglomerated clusters (Fig. 3, sample J_1). A similar effect was also observed in the case of series $\mathbf{J} \_\mathbf{4}$ and $\mathbf{J} \_\mathbf{5}$ for which one of the layers is a DLC:Si layer. The agglomerated structure was also observed by Zhang et al. [29], who obtained an DLC:Si structure on monocrystalline silicone (100) with the clusters that were not an effect of the rough surface of polyurethane. Leal et al. [30] obtained DLC:N structures on the same substrate and the investigations proved that increasing the concentration of nitrogen in the gas mixture from 40 to $60 \mathrm{vol} \%$ caused an increase in the roughness. In our research, the concentrations of nitrogen in the gas mixture were 83 vol\% (J_2) and 80 vol.\% (J_3). In these cases, the surface roughness $\left(R_{\mathrm{a}}\right)$ was really low, 0.352 and $0.328 \mathrm{~nm}$, respectively. However, the significant increase in the roughness parameters was observed in the multilayer coatings, whose topography was connected with the outer DLC:Si or DLC:N layer. More details concerning the surface roughness values of all the samples, the size of grains and the layer thicknesses are presented in Table 1 and Fig. 4.

The cross-sectional morphology of the double-layer sample $\mathbf{J} \_\mathbf{5}$ is presented in Fig. 4. It can be clearly seen that the DLC:N outer layer is ca. $3.8 \mu \mathrm{m}$ thick and the DLC:Si inner layer is ca. $4.7 \mu \mathrm{m}$ thick. Because the time of deposition of both layers was the same, $30 \mathrm{~min}$, this result indicates that the DLC:N layer growth rate was slower in comparison to the layer doped with nitrogen. A similar relationship was observed for the sample $\mathbf{J} \_4$ (Table 1). In this case, the DLC:Si outer layer is ca. $4.7 \mu \mathrm{m}$ thick and the DLC:N inner layer is ca. $3.8 \mu \mathrm{m}$ thick. Additionally, Fig. 4 also partially showed granular-like top surface morphology of the presented sample.

The roughness of the obtained monolayers differed depending on the element, which was doped into the structure. The roughness $\left(\mathrm{R}_{\mathrm{a}}\right.$ value) of the DLC doped with

Table 1 The grain size, surface roughness $\left(R_{\mathrm{a}}\right)$ and layer thickness ( $d$ ) of the modified PU with the obtained coatings; $R_{\mathrm{a}}$ - data based on AFM measurements

\begin{tabular}{lllll}
\hline Series & $\begin{array}{l}\text { Grain size }(\mathrm{nm}) \\
\text { Small }\end{array}$ & Large & $R_{\mathrm{a}}(\mathrm{nm})^{*}$ & $d(\mu \mathrm{m})$ \\
\hline J_1 & $49 \pm 16$ & $176 \pm 37$ & $4.125 \pm 0.065$ & $4.45 \pm 0.35$ \\
J_2 & - & - & $0.352 \pm 0.013$ & $3.77 \pm 0.12$ \\
J_3 & - & - & $0.328 \pm 0.072$ & $3.85 \pm 0.10$ \\
J_4 & $46 \pm 19$ & $266 \pm 91$ & $5.040 \pm 0.110$ & $8.40 \pm 0.55^{*}$ \\
J_5 & $49 \pm 22$ & $238 \pm 60$ & $9.130 \pm 0.840$ & $8.55 \pm 0.45^{* *}$ \\
\hline
\end{tabular}

*The thickness of the DLC:N and DLC:Si layers was ca. $3.80 \mu \mathrm{m}$ and ca. $4.60 \mu \mathrm{m}$, respectively

** The thickness of the DLC:Si and DLC:N layers was ca. $4.70 \mu \mathrm{m}$ and ca. $3.85 \mu \mathrm{m}$, respectively
Fig. 3 The AFM images (3D) of the selected PU surfaces: J_1 after DLC:Si deposition $\left(\mathrm{SiH}_{4} /\right.$ $\left.\mathrm{CH}_{4} / \mathrm{Ar}=1 / 1 / 10\right)$, J_2 after DLC: $\mathrm{N}$ deposition $\left(\mathrm{N}_{2} / \mathrm{CH}_{4} /\right.$ $\mathrm{Ar}=10 / 1 / 1), \mathbf{J} \_3$ after DLC:N deposition $\left(\mathrm{N}_{2} / \mathrm{CH}_{4} / \mathrm{Ar}=8 / 1 / 1\right)$, J_4 after DLC:N and DLC:Si deposition, J_5 after DLC:Si and DLC:N deposition
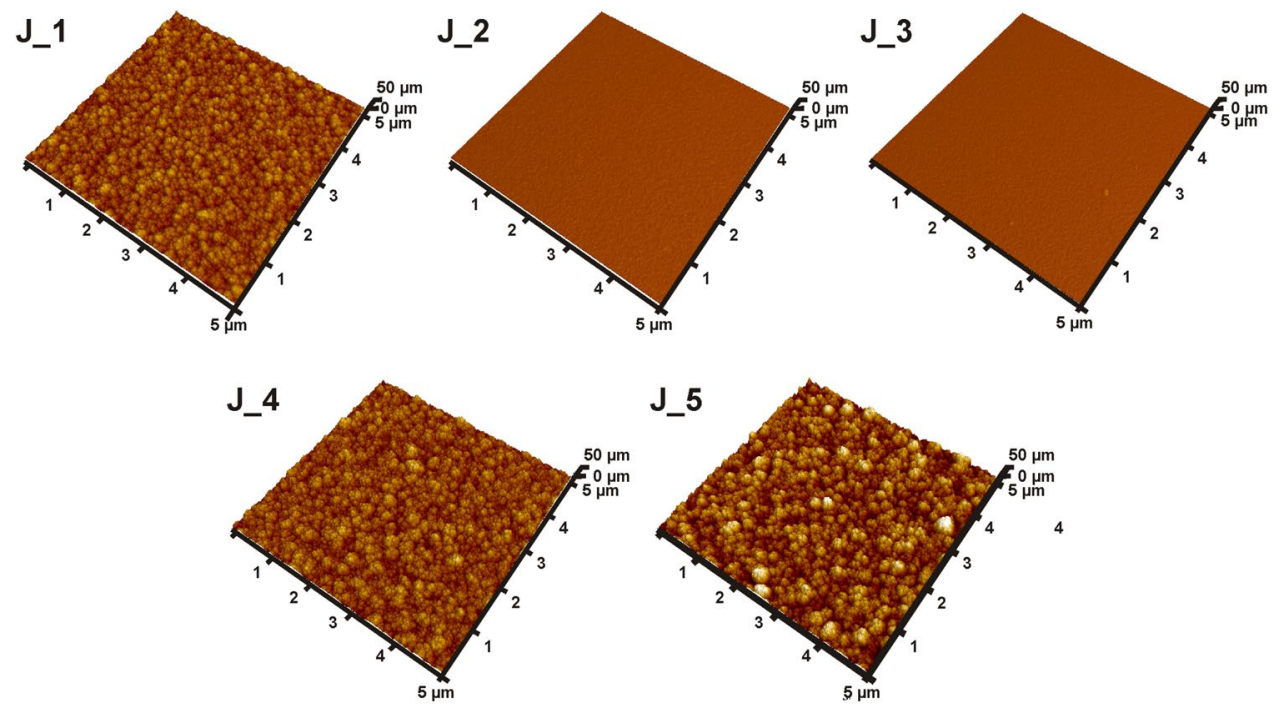

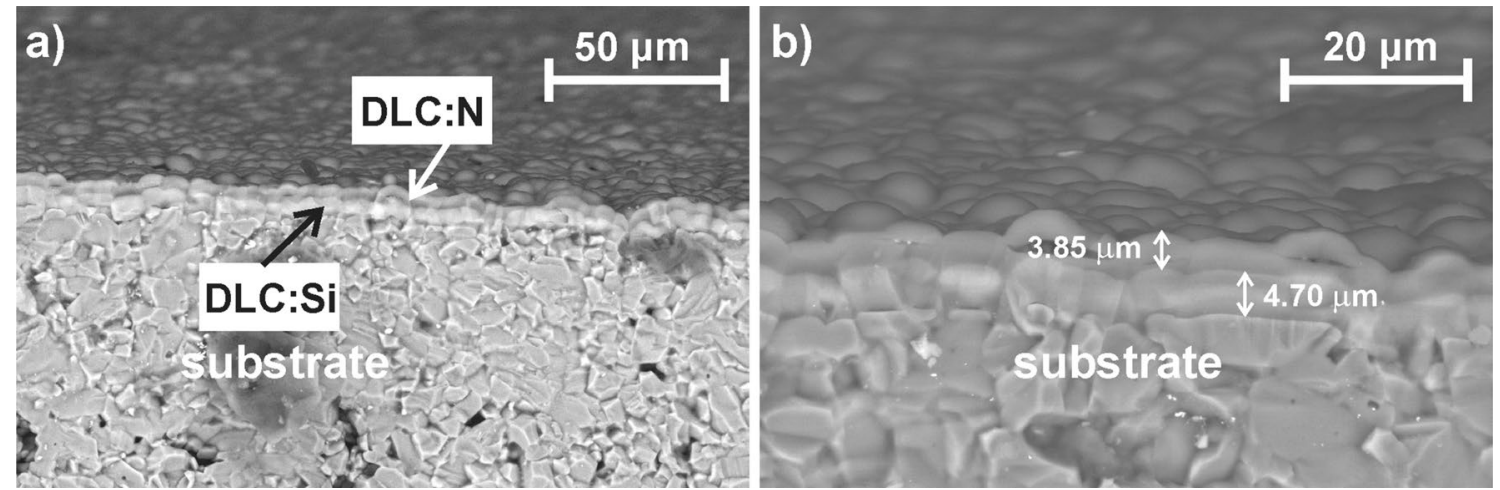

Fig. 4 The cross-sectional images (SEM) of the selected modified substrate (J_5) after the plasma processes, $\mathrm{DLC}_{\mathbf{S}} \mathrm{Si}\left(\mathrm{SiH}_{4} / \mathrm{CH}_{4} / \mathrm{Ar}=1 / 1 / 10\right)$ and DLC: $\mathrm{N}\left(\mathrm{N}_{2} / \mathrm{CH}_{4} / \mathrm{Ar}=10 / 1 / 1\right)$ layer deposition: a magnification $1000 \times$, b magnification $2600 \times$

silicon is almost 12 times higher than that of the structures doped with nitrogen. What is noteworthy, our research shows that it is possible to control the surface roughness of the obtained structures in multilayer systems. Deposition of DLC:Si in both samples $\mathbf{J} \_\mathbf{4}$ and $\mathbf{J} \_\mathbf{5}$ was performed under the same plasma conditions. Importantly, depending on the order of DLC:Si layer deposition, in the case of $\mathbf{J} \_\mathbf{5}$ the observed surface roughness was almost twice as high as that for the $\mathbf{J} \mathbf{4}$ series. This is very important for the osteointegration of an implant with bone tissue, since the osteointegration process depends on the surface roughness in both the nano and a larger scale [4]. Relatedly, the study was supplemented by an analysis of the surface profile of the resulting samples using an optical profilometer. The investigation confirmed that the highest value of the $R_{z}$ parameter $(32.338 \pm 3.692 \mu \mathrm{m})$ was observed in the case of $\mathbf{J} \_5$ series, while the lowest value $(12.582 \pm 4.341 \mu \mathrm{m})$ for the $\mathbf{J} \_2$ series. The selected stereometric graphs of the tested surface samples are presented in Fig. 5.
An analysis of the chemical composition (Fig. 6) of the tested samples confirms that the obtained coatings consisted of $\mathrm{C}, \mathrm{N}, \mathrm{O}$ and Si elements, depending on the chemical composition of the gas mixture used in the plasma processes in the PE reactor. In the case of the $\mathbf{J}_{-} \mathbf{1}$ series (with the DLC:Si coating), silicon was incorporated into the structure to ca. 35 at.\%, while nitrogen (for the $\mathbf{J} \_\mathbf{2}$ and $\mathbf{J} \_\mathbf{3}$ series) in the DLC:N structure was incorporated to ca. 9.5 at.\% and 0.2 at.\%, respectively. These differences in nitrogen content were also confirmed by the IR-ATR technique (vide infra, Fig. 7a). The lower content of nitrogen in sample $\mathbf{J} \_\mathbf{3}$ was probably caused by a higher RF power value in the plasma processes, as well as a lower $\mathrm{N}_{2}$ content in the gas mixture. In the case of $\mathbf{J} \mathbf{4}$, the thickness of DLC:Si layer was above $1 \mu \mathrm{m}$ and the nitrogen content in the obtained coatings was out of the range of EDS analysis.

In the modified substrates after the plasma processes, a relatively high content of oxygen atoms, ca. 30.5 at. \%, 5.2 at. $\%, 7.8$ at. $\%, 28.3$ at. $\%, 23.0 \%$ at. for samples $\mathbf{J} \_\mathbf{1}$ to $\mathbf{J} \_5$, respectively, with reference to ca. 13.5 at.\% for the
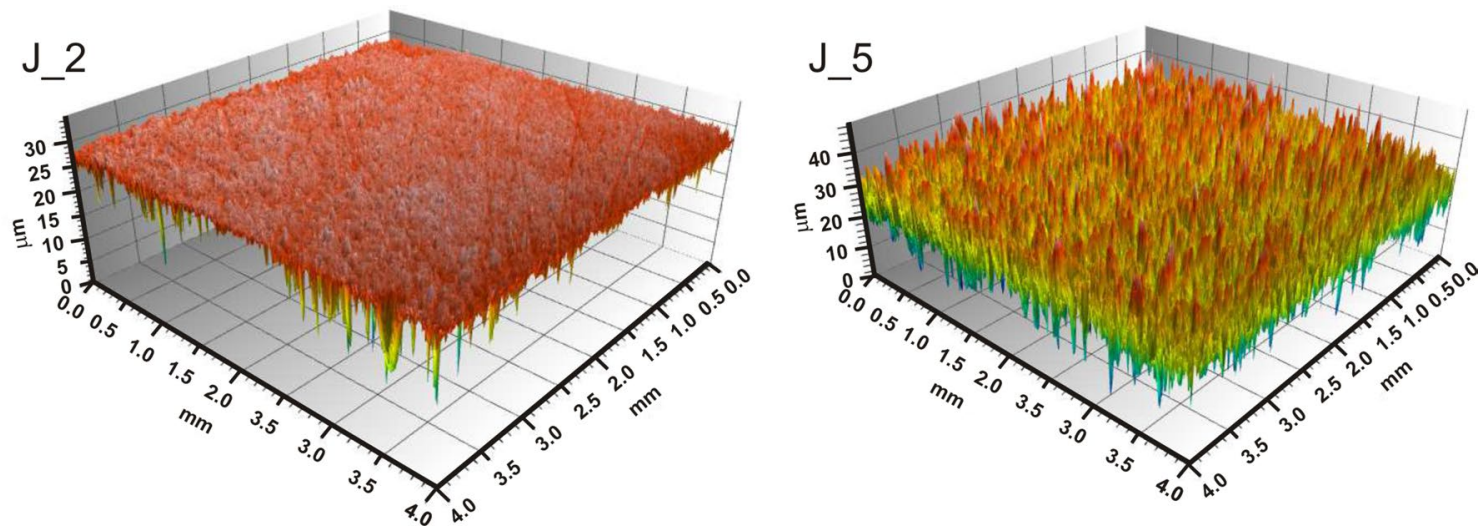

Fig. 5 The surface topographies of the tested PU surfaces: $\mathbf{J} \_\mathbf{2}$ after DLC:N deposition $\left(\mathrm{N}_{2} / \mathrm{CH}_{4} / \mathrm{Ar}=10 / 1 / 1\right)$ and $\mathbf{J} \_\mathbf{5}$ after $\mathrm{DLC}: \mathrm{Si}\left(\mathrm{SiH} \mathrm{H}_{4} / \mathrm{CH}_{4} /\right.$ $\mathrm{Ar}=1 / 1 / 10)$ and DLC:N $\left(\mathrm{N}_{2} / \mathrm{CH}_{4} / \mathrm{Ar}=10 / 1 / 1\right)$ deposition 


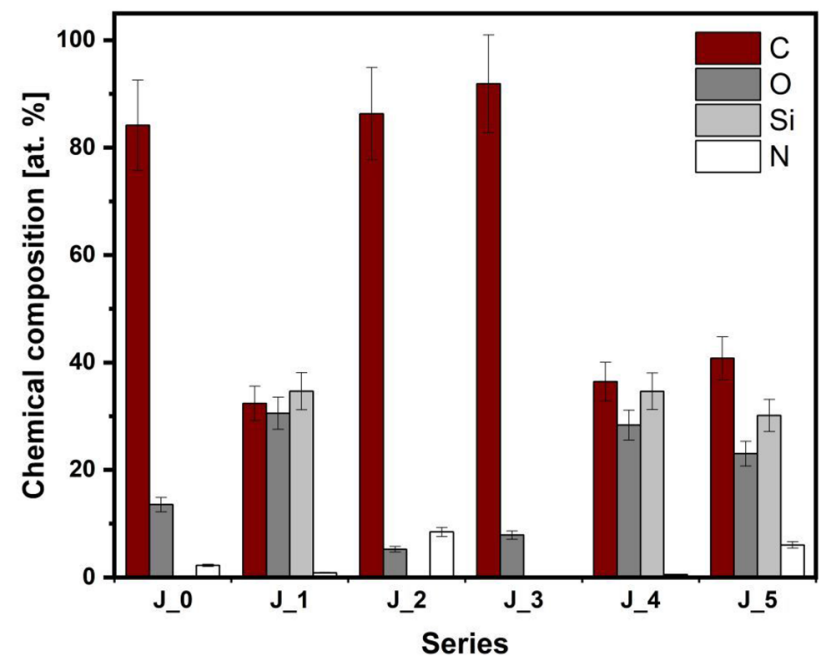

Fig. 6 The chemical composition (average values \pm 0.1 at. $\%$ ) of the tested PU surfaces: J_0 unmodified, J_1 after DLC:Si deposition $\left(\mathrm{SiH}_{4} / \mathrm{CH}_{4} / \mathrm{Ar}=1 / 1 / 10\right), \mathbf{J} \_2$ after DLC:N deposition $\left(\mathrm{N}_{2} / \mathrm{CH}_{4} /\right.$ $\mathrm{Ar}=10 / 1 / 1), \mathbf{J} \_3$ after DLC:N deposition $\left(\mathrm{N}_{2} / \mathrm{CH}_{4} / \mathrm{Ar}=8 / 1 / 1\right), \mathbf{J} \_\mathbf{4}$ after DLC:N and DLC:Si deposition, J_5 after DLC:Si and DLC:N deposition unmodified substrate (J_0) was observed. The growth of oxygen concentration after the plasma treatments is strongly affected by the creation of polar oxygen groups, which was also concluded by Novotná et al. [31]. In the case of $\mathbf{J} \_\mathbf{1}, \mathbf{J} \_\mathbf{4}$ and $\mathbf{J} \_\mathbf{5}$ series (all with a DLC:Si layer), oxygen appeared in the EDS analysis (up to ca. 30 at. \%), probably as a result of adsorption of this element after the coating deposition process under ambient air conditions or the presence of oxygen in voids/microcracks existing in highly roughed surfaces of these samples. In the case of other series, with only the DLC:N layers $\left(\mathbf{J} \_\mathbf{2}\right.$ and $\left.\mathbf{J} \_\mathbf{3}\right)$, this effect was not observed (oxygen atoms up to ca. 8 at. \%). Another possible explanation of relatively high concentration of oxygen was attributed to the surface oxidation of the modified substrates after the deposition process, also observed by Batory et al. [32]. This corresponds to the presence of the $\mathrm{Si}-\mathrm{O}$ atomic groups in the IR spectra (vide infra, Fig. 7) and is probably caused by a very high binding energy for $\mathrm{Si}-\mathrm{O}$ (ca. $532 \mathrm{eV}$ ), compared to the value for $\mathrm{C}-\mathrm{H}$ (ca. $338.5 \mathrm{~kJ} / \mathrm{mol}$ ) and $\mathrm{Si}-\mathrm{H}$ (ca. $298.7 \mathrm{~kJ} / \mathrm{mol}$ ) [33]. Therefore, it can be concluded that $\mathrm{Si}-\mathrm{H}$ bonds are less stable than $\mathrm{C}-\mathrm{H}$ bonds, which also
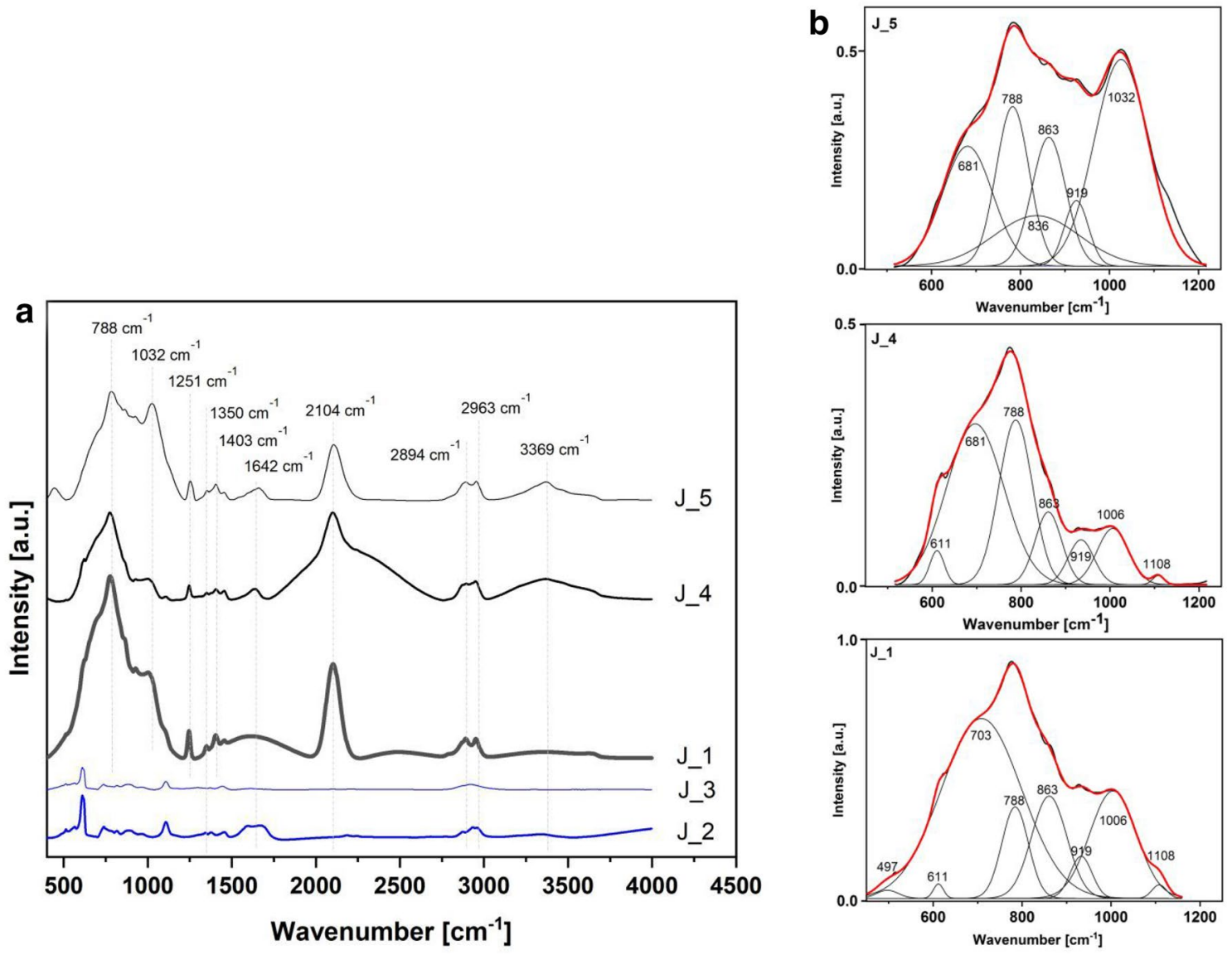

Fig. 7 a The IR-ATR spectra of PU substrates after layer deposition: J_1 after DLC:Si deposition $\left(\mathrm{SiH}_{4} / \mathrm{CH}_{4} / \mathrm{Ar}=1 / 1 / 10\right)$, J_2 after DLC:N deposition $\left(\mathrm{N}_{2} / \mathrm{CH}_{4} / \mathrm{Ar}=10 / 1 / 1\right), \mathbf{J} \_\mathbf{3}$ after DLC:N deposi- tion $\left(\mathrm{N}_{2} / \mathrm{CH}_{4} / \mathrm{Ar}=8 / 1 / 1\right), \mathbf{J} \_4$ after DLC:N and DLC:Si deposition, J_5 after DLC:Si and DLC:N deposition and $\mathbf{b}$ deconvolution of the bands in the range $450 \mathrm{~cm}^{-1}-1200 \mathrm{~cm}^{-1}$ for the selected IR spectra 
confirms the benefits of incorporation of oxygen into the DLC:Si structure.

\subsection{FTIR-ATR analysis}

The atomic structure of modified polyurethane surface was analyzed using the FTIR-ATR method, and the obtained results are shown in Fig. 7a, b.

In general, during plasma processes (etching, grafting polymerization, layers deposition, etc.) the design of precisely determined functional surface coatings for many substrates, including polymeric $[34,35]$ is possible. The reordered IR spectra of modified PU substrates represent the two groups of obtained coatings, without the DLC:Si layers ( $\mathbf{J} \_\mathbf{2}$ and $\mathbf{J} \_\mathbf{3}$ series, a smaller value of absorption peaks) and with the DLC:Si layers (J_1, J_4 and $\mathbf{J} \_5$ series, a higher value of absorption peaks). In the case of the only DLC:N layers ( $\mathbf{J} \_\mathbf{2}$ and $\mathbf{J} \_\mathbf{3}$ series), two relatively weak (about two times lower in comparison with the IR spectra for the other experimental series) spectra bands (with a maximum at $2963 \mathrm{~cm}^{-1}$ and $2873 \mathrm{~cm}^{-1}$ ) were observed and attributed to asymmetric and symmetric stretching vibrations in the $\mathrm{CH}_{2}$ group, respectively. The bandwidth means that they contained different types of $\mathrm{C}-\mathrm{H}$ bonds, such as $\mathrm{Csp}^{3}-\mathrm{H}_{\mathrm{n}}\left(-\mathrm{CH}=,-\mathrm{CH}_{2}-,-\mathrm{CH}_{3}\right)$, and $\mathrm{Csp}^{2}-\mathrm{H}_{\mathrm{n}}$ $\left(\mathrm{C}=\mathrm{CH}, \mathrm{C}=\mathrm{CH}_{2}\right)$. These vibrations are typical of DLC structures and correspond to $\mathrm{C}-\mathrm{H}$ asymmetric and symmetric stretching vibrations $[18,36]$. For the $\mathbf{J} \_\mathbf{2}$ series, in the range of $1580 \mathrm{~cm}^{-1}$ to $1680 \mathrm{~cm}^{-1}, \mathrm{C}=\mathrm{C}$ and $\mathrm{C}=\mathrm{N}$ bonds can be noticed [37], which in the case of $\mathbf{J} \_\mathbf{2}$ can also be attributed to $\mathrm{NH}$ and $\mathrm{NH}_{2}$ bonds vibrations (in the energy range $1500 \mathrm{~cm}^{-1}-1600 \mathrm{~cm}^{-1}$ ) [38]. In the case of the next modification (with the DLC:Si layer deposition), new spectra lines were observed. The spectra were dominated by different atomic groups containing $\mathrm{Si}$ atoms, in the range $450 \mathrm{~cm}^{-1}-1162 \mathrm{~cm}^{-1}$ (see Fig. 7b). The peak at $611 \mathrm{~cm}^{-1}$ may be assigned to the $\mathrm{C}-\mathrm{H}$ bending vibrations and the peak at $681 \mathrm{~cm}^{-1}$ (as well as $863 \mathrm{~cm}^{-1}$ ) probably corresponds to the $\mathrm{Si}-\mathrm{H}$ wagging bonds [39]. Relatively strong bands observed at ca. $703 \mathrm{~cm}^{-1}$ as well as at $1032 \mathrm{~cm}^{-1}$ and $788 \mathrm{~cm}^{-1}$ are attributed to the $\mathrm{Si}-\mathrm{CH}_{3}$ and $\mathrm{Si}-\left(\mathrm{CH}_{3}\right)_{2}$ stretching vibrations, respectively [38]. The band observed at $919 \mathrm{~cm}^{-1}$ is assigned to the $\mathrm{Si}-\mathrm{N}$ stretching vibrations [38]. The spectra lines at $1006 \mathrm{~cm}^{-1}$ and $1108 \mathrm{~cm}^{-1}$ correspond to the $\mathrm{Si}-\mathrm{CH}_{2}$ deformation modes and the $\mathrm{Si}-\mathrm{O}-\mathrm{C}$ or $\mathrm{Si}-\mathrm{O}-\mathrm{Si}$ bonds, respectively [40]. Additionally, the strong peak centered at $2104 \mathrm{~cm}^{-1}$ (assigned to the $\mathrm{Si}-\mathrm{H}$ group [39]) and the peak at $1250 \mathrm{~cm}^{-1}$ (assigned to the $\mathrm{Si}-\mathrm{CH}_{3}$ atomic group $[38,41]$ ) were observed. In the case of the $\mathbf{J} \_\mathbf{4}$ and $\mathbf{J} \_\mathbf{5}$ series (after the DLC:Si and DLC:N deposition in various configurations), the relatively strong spectra lines are centered at $3369 \mathrm{~cm}^{-1}$. These absorption phenomena may be assigned to the $\mathrm{NH}$ and $\mathrm{NH}_{2}$ groups (in the energy range
$3300 \mathrm{~cm}^{-1}-3400 \mathrm{~cm}^{-1}$ ) and also confirmed by a spectra line at ca. $1350 \mathrm{~cm}^{-1}[33,41]$. On the other hand, in this range of energy, i.e., $3200 \mathrm{~cm}^{-1}-3400 \mathrm{~cm}^{-1}$, especially in the case of modification with the DLC:Si layers, deposition spectra lines may be assigned more probably to the $\mathrm{O}-\mathrm{H}$ groups. Additionally, the high value of oxygen content in the cases of $\mathbf{J} \_\mathbf{1}, \mathbf{J} \_\mathbf{4}$ and $\mathbf{J} \_\mathbf{5}$ (between ca. 22 and 35 at. $\%$ ) is presumably related to the vibrations in the $\mathrm{Si}-\mathrm{O}$ in $\mathrm{Si}-\mathrm{O}-\mathrm{Si}$ groups, which was assigned also to the $1034 \mathrm{~cm}^{-1}$ spectral line [38]. Our previous study [27, 42] confirmed that in the case of polymeric substrates modified with DLC:Si layers, the high dissociation energy of the $\mathrm{Si}-\mathrm{O}$ bonding equal to $798 \mathrm{~kJ} \mathrm{~mol}^{-1}$ resulted in a significant increase in the mechanical resistance of the modified surface. All the modifications of the PU substrates also resulted in the appearance of a spectra line for $1642 \mathrm{~cm}^{-1}$ that is assigned to the vibrations in the $\mathrm{C}=\mathrm{C}$ and $\mathrm{C}=\mathrm{N}$ groups $[43,44]$. It can be concluded that DLC:Si layers are formed more readily, with higher growth rate, on the PU substrate than DLC:N layers and the obtained IR spectra showed much higher intensities of spectral lines for the $\mathrm{CH}_{\mathrm{n}}$ groups $(n=1,2$ and 3, in the energy range ca. $2850-3000 \mathrm{~cm}^{-1}$ ). In addition, obtaining the DLC:Si layer in the first step of surface modification is beneficial for the growth of subsequently deposited DLC:N layer ( $\mathbf{J} \_\mathbf{5}$ series) on the PU substrate, compared to the $\mathbf{J} \_\mathbf{2}$ or $\mathbf{J} \_\mathbf{3}$ series (modified by a single DLC:N layer). In the case of the $\mathbf{J} \_5$ series (after DLC:Si and DLC:N deposition), a strong increase in the number of $\mathrm{Si}-\left(\mathrm{CH}_{3}\right)_{2}$ groups were observed. This effect is probably related to the surface roughness value $\left(R_{\mathrm{a}} c a .9 \mathrm{~nm}\right)$ of modified $\mathrm{PU}$, which is almost twice as high as in the case of $\mathrm{J}_{-} 2$ series $\left(R_{\mathrm{a}} c a\right.$. $5 \mathrm{~nm})$.

\subsection{Contact angle and SFE analysis}

Unmodified polyurethane is a hydrophobic material and is characterized by hydrolytic and enzymatic degradation. Therefore, surface modifications of these substrates are particularly important for practical biomechanical applications. In the case of biomedical applications, one of the significant surface parameters is wettability, as a hydrophilic surface is responsible for cell adhesion and biocompatibility [45]. On the other hand, a hydrophobic surface is characterized by better antibacterial properties as regards bacteria reluctance required to create a biofilm [46]. The wettability determined by the value of the water contact angle is an important variable for the antibacterial character of the resulting layers and allowing the formation of the biofilm. Figure 8a shows the measured values of water diiodomethane contact angles for all the studied series (J_0-J_5).

All the series were characterized by water and diiodomethane contact angles in the range from ca. 65 to 120 degrees. An increase in the contact angle values was 


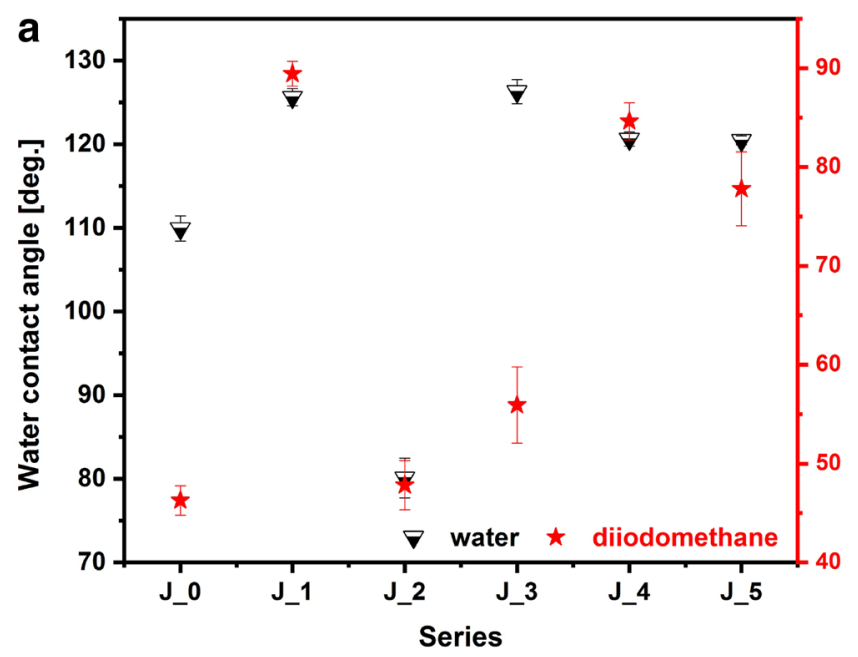

Fig. 8 The water and diiodomethane contact angles a and the surface free energy $\left(\gamma_{\text {tot }}\right.$ - total, $\gamma_{\mathrm{d}}$ - dispersive part, $\gamma_{\mathrm{p}}$-polar part $)$ values b of unmodified PU substrates: J_0 unmodified, J_1 after DLC:Si deposition $\left(\mathrm{SiH}_{4} / \mathrm{CH}_{4} / \mathrm{Ar}=1 / 1 / 10\right)$, J_2 after DLC:N deposition $\left(\mathrm{N}_{2} /\right.$

observed for all the tested series after the deposition of the DLC-based structures, apart from the $\mathbf{J} \_\mathbf{2}$ series (with the resulting DLC:N layer with the highest content of nitrogen in the DLC structure, $c a$. 9.5 at.\%) -Fig. 8a. A significantly higher increase was observed for diiodomethane apart from the samples $\mathbf{J} \_\mathbf{2}$ and $\mathbf{J} \_\mathbf{3}$. As regards the $\mathbf{J} \_\mathbf{3}$ series water contact angle has a higher value in comparison to the $\mathbf{J} \_\mathbf{2}$ series. It can be explained by the difference in chemical composition, i.e., a higher amount of nitrogen in $\mathbf{J} \_\mathbf{2}$, and the difference in atomic structures of the surfaces of both series with single DLC:N layer. Significantly, the modifications containing the DLC:Si layers exhibited the highest hydrophobic properties for the two liquids, i.e., water and diiodomethane. Such layers containing Si tended to increase the water contact angle, i.e., becoming more hydrophobic. A similar effect was confirmed by Ahmed et al. [47]. Wettability may thus play an important role in increasing human serum albumin adsorption on the DLC:Si film surface, because a more hydrophobic surface reduces its interaction with water molecules, allowing for more direct contact with the protein. On the other hand, a more hydrophilic surface would promote its interaction with water, and thus increase the adsorption layer [48]. Figure $8 b$ shows the results of the surface free energy values obtained for the tested samples, including the polar and dispersive components of the SFE. A significant decrease in the surface free energy after the modification using the silicon-doped DLC structure (the J_1 series) as well as including the multilayer systems (the $\mathbf{J} \_\mathbf{4}$ and $\mathbf{J} \_\mathbf{5}$ series) in relation to the unmodified PU was observed. For both experimental series, the total $\left(\gamma_{\text {tot. }}\right)$ and polar $\left(\gamma_{\mathrm{p}}\right)$ components of the surface free energy had similar values, the polar component not exceeding ca. $0.5 \mathrm{~mJ} \mathrm{~m}^{-2}$.

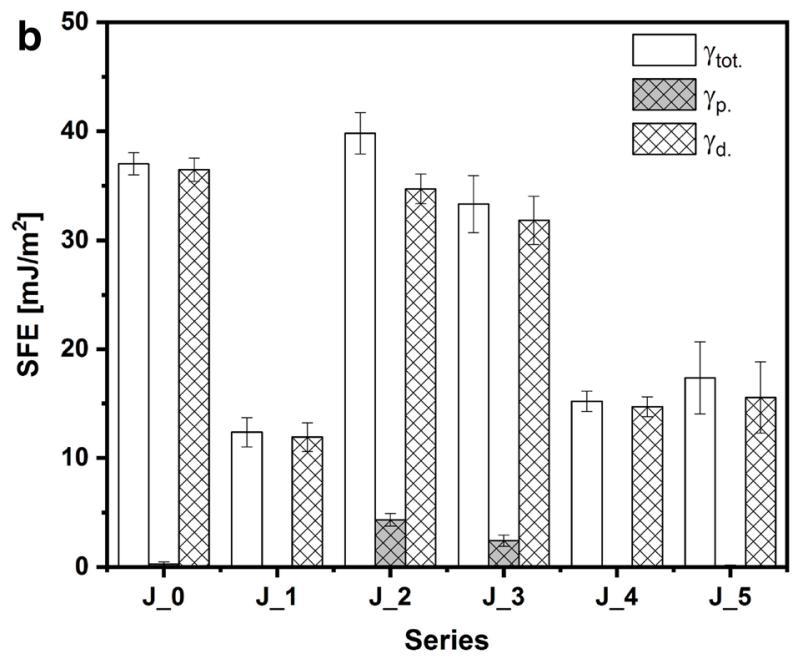

$\left.\mathrm{CH}_{4} / \mathrm{Ar}=10 / 1 / 1\right), \mathbf{J} \_3$ after DLC:N deposition $\left(\mathrm{N}_{2} / \mathrm{CH}_{4} / \mathrm{Ar}=8 / 1 / 1\right)$, J_4 after DLC:N and DLC:Si deposition, J_5 after DLC:Si and DLC:N deposition

Additionally, in the case of $\mathbf{J} \_\mathbf{2}$ and $\mathbf{J} \_\mathbf{3}$ series (after DLC:N layers deposition only), we observed an increase in the polar component SFE as a result of the incorporation of the polar functional groups without significantly changing (or with a small decrease) the dispersive component of the SFE. The highest value (ca. $5.0 \mathrm{~mJ} \mathrm{~m}^{-2}$ ) of $\gamma_{\mathrm{p}}$ was noted for the DLC:N layers in the $\mathbf{J} \_\mathbf{2}$ series deposited at the $\mathrm{Ar} / \mathrm{N}_{2} / \mathrm{CH}_{4}$ ratio in the gas mixture of 8/80/8. Most importantly, in these cases the tested surfaces had the lowest roughness values $\left(R_{\mathrm{a}}\right.$ below $0.355 \mathrm{~nm}$ ). It can be concluded that the total SFE of modified PU substrates with Si-doped DLC layers decreased significantly, whereas only the deposition of the N-doped DLC layers on the PU substrate resulted in the highest $\gamma_{\text {tot. }}$ value and the lowest contact angle value. This should improve the biocompatibility of the studied polymeric substrates. Based on the performed research, we concluded that the DLC-based coatings deposited on PU substrates can be used for an increase of surface wettability as well as improving cell adhesion, depending on the applied processes in the reactor ( $\mathrm{Si}$ or $\mathrm{N}$ doping of the DLC structure, layers in various configuration). The processes with DLC:Si layers deposition provide a granular-like surface morphology that favors surface hydrophobicity. This is consistent with the activation of polymer surface with the application of the $\mathrm{Ar}$ or $\mathrm{O}_{2}$ gas atmosphere that does not lead to the creation of the polar groups and increased hydrophilicity. These results can be explained by the reorganization of the PU surface during plasma etching and newly deposited DLC-based layers. The increase in the SFE polar component accompanied by the lower contact angles is observed only when DLC:N layers are obtained. The above-mentioned physicochemical properties are the result of low $R_{\mathrm{a}}$ parameters (up to $c a$. 
$0.3 \mathrm{~nm}$ ) of the obtained DLC:N structures of $\mathbf{J} \_\mathbf{2}$ and $\mathbf{J} \_\mathbf{3}$ series and the presence of the $\mathrm{C}-\mathrm{H}$ and $\mathrm{C}-\mathrm{N}$ groups on the polymer surface.

\subsection{Cytotoxicity study}

The influence of PU substrates modified under plasma conditions using DLC-based layers (doped $\mathrm{Si}$ or $\mathrm{N}$ atoms) on the viability of human osteoblast-like cells (MG-63) and human somatic cells (keratinocytes, $\mathrm{HaCaT}$ ) was monitored in vitro during $72 \mathrm{~h}$ under a fluorescence inverted microscope. Selected images of MG-63 treated cells with the unmodified and modified polyurethane for $72 \mathrm{~h}$ are presented in Fig. 9.

The cells were stained with fluorescein diacetate (FDA) and propidium iodide (PI) indicating viable and dead necrotic or late apoptotic cells, respectively. No morphological changes in the cells were seen in the case of all the tested samples. No significant changes in the mitochondrial shape and size, and no apoptotic bodies were observed after the incubation with the PU substrates modified under plasma conditions using the DLC-based layers (doped Si or $\mathrm{N}$ atoms).

The Alamar Blue assay, a quantitative indicator of the proliferation of cells, revealed no significant reduction in the cell growth after the treatment with the tested samples. The observed surviving reduction was not higher than $12 \%$ for all the modifications (Fig. 10).

The highest cytotoxic influence on the MG-63 cell viability was observed for the $\mathbf{J} \_\mathbf{3}$ series after the modification using the DLC:N layers deposited at the $\mathrm{Ar} / \mathrm{N}_{2} / \mathrm{CH}_{4}$ ratio in the gas mixture of 10/80/10 (ca. 11\%), whereas, in the case of HaCat cells, the cytotoxicity did not exceed (ca. 12\%) for the same series of the tested samples. The cytotoxicity and cell morphology analyses using the osteoblast cell line MG-63 and human somatic cells (HaCat) showed that PU/ DLC-based layers are suitable materials for cell growth and differentiation.

The proposed coatings (DLC:N and/or DLC:Si in various configurations) on the PU substrates are less cytotoxic

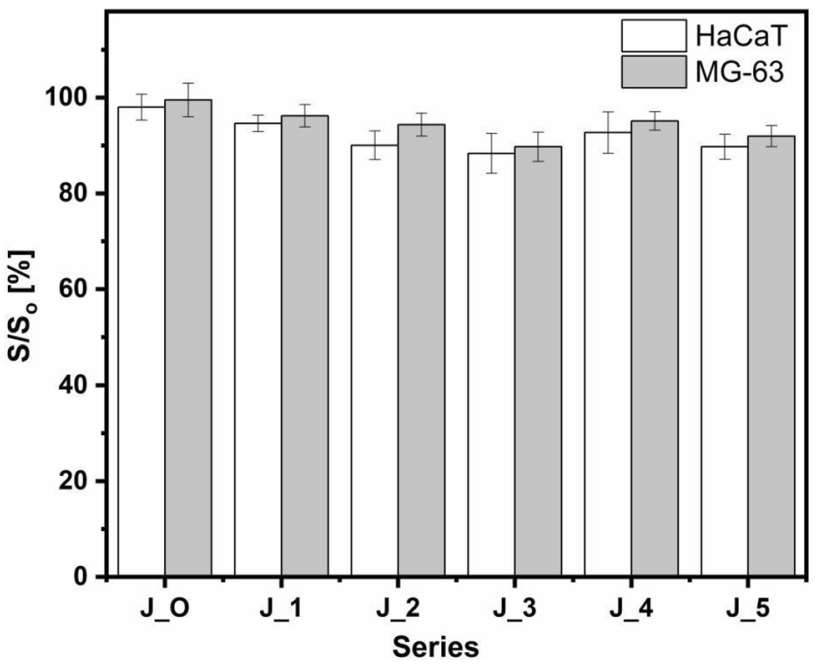

Fig. 10 The relative growth rates of MG-63 and HaCaT cells assessed by the Alamar Blue test and expressed by the surviving fraction $\left(\mathrm{S} / \mathrm{S}_{0} \%\right)$ after $72 \mathrm{~h}$ of incubation on the tested samples: $\mathbf{J} \_\mathbf{0}$ unmodified, J_1 after DLC:Si deposition $\left(\mathrm{SiH}_{4} / \mathrm{CH}_{4} / \mathrm{Ar}=1 / 1 / 10\right)$, J_2 after DLC:N deposition $\left(\mathrm{N}_{2} / \mathrm{CH}_{4} / \mathrm{Ar}=10 / 1 / 1\right)$, J_3 after DLC:N deposition $\left(\mathrm{N}_{2} / \mathrm{CH}_{4} / \mathrm{Ar}=8 / 1 / 1\right), \mathbf{J} \_\mathbf{4}$ after DLC:N and DLC:Si deposition, J_5 after DLC:Si and DLC:N deposition. The values are represented as mean $\pm \mathrm{SD}$ of three individual experiments

than the DLC:N:Si layers previously studied by us and those deposited on titanium alloy [49]. The latter coatings influenced the viability of treated MG-63 cells, decreasing the cell surviving fraction even up to $c a$. 29\% (modification " $\mathrm{C}$ " after the nitriding process and DLC:N:Si deposition). It can be concluded that the application of the DLC:Si and DLC:N layer systems resulted in a lower cytotoxic effect than the addition of $\mathrm{N}$ and $\mathrm{Si}$ atoms to the DLC structure during coating deposition.
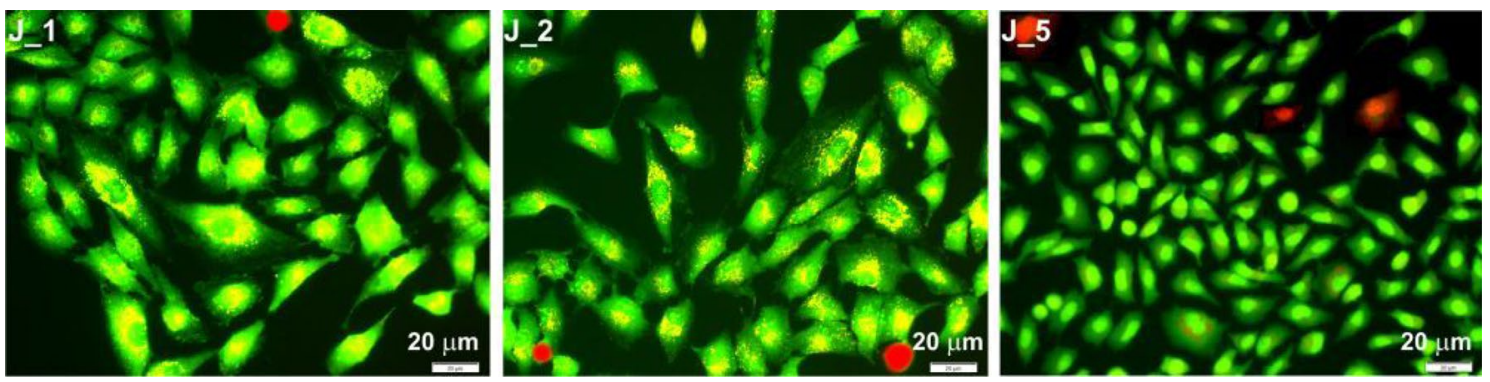

Fig. 9 The human osteoblast-like MG-63 cells after 72-h incubation on polyurethane: J_1 after DLC:Si deposition $\left(\mathrm{SiH}_{4} / \mathrm{CH}_{4} /\right.$ $\mathrm{Ar}=1 / 1 / 10), \mathbf{J} \_2$ after DLC:N deposition $\left(\mathrm{N}_{2} / \mathrm{CH}_{4} / \mathrm{Ar}=10 / 1 / 1\right)$ as well as $\mathbf{J} \_5$ after DLC:Si $\left(\mathrm{SiH}_{4} / \mathrm{CH}_{4} / \mathrm{Ar}=1 / 1 / 10\right)$ and DLC:N $\left(\mathrm{N}_{2} /\right.$ $\left.\mathrm{CH}_{4} / \mathrm{Ar}=10 / 1 / 1\right)$ deposition; the live (green) and the dead (red) 


\section{Conclusions}

The obtained DLC:Si and/or DLC:N single and multilayers on the surface of polyurethane were continuous and exhibited good adherence to PU substrates. They were characterized by an amorphous structure and homogeneity of chemical composition. The maximum incorporation of silicon and nitrogen atoms in the DLC structure was observed up to ca. 35 at.\% (DLC:Si, series J_1) and up to ca. 9.5 at.\% (DLC:N, series $\left.\mathbf{J} \_2\right)$, respectively. Topography analysis showed the granular-like structures of deposited DLC:Si layers, composed of agglomerated clusters up to maximum grain size ca. $270 \mathrm{~nm}$. On the other hand, the analysis of the resulting DLC:N layers revealed that they exhibited significantly less developed area surface in the cases of single layers $\left(\mathbf{J} \_\mathbf{2}\right.$ and J_3 series). The maximum value of surface roughness $\left(R_{\mathrm{a}}\right)$ being 0.352 for $\mathbf{J} \_2$ formed in the reaction gas mixture containing $80 \%$ vol. of $\mathrm{N}_{2}$. This significant difference between the $R_{\mathrm{a}}$ parameters for the deposited DLC layers is connected with their chemistry and growth mechanisms. The addition of Si to the DLC structure promoted the formation ca. two times higher content of terminal $\mathrm{CH}_{\mathrm{n}}$ bonds $(n=1,2,3)$ in comparison with the other experimental series (after deposition DLC:N only) as well as beneficial $\mathrm{Si}-\mathrm{H}$ and $\mathrm{Si}-\mathrm{CH}_{\mathrm{n}}$ bonds, which significantly reduced the internal stresses in the coating and increased the growth rates of the obtained structures. The plasma depositions of single DLC:Si layers and all multilayers resulted in a much higher values of diiodomethane contact angle (up to ca. $90^{\circ}$ for series $\mathbf{J} \_\mathbf{1}$ ) compared with the single DLC:N layer (up to ca. $55^{\circ}$ for series $\mathbf{J} \_3$ ). The results regarding the measurements of the contact angles are in agreement with the determined polar parts of the surface free energy of the layers.

The obtained DLC-based coatings were characterized by higher hydrophobicity than unmodified PU, good biocompatibility, and different topographies (nanometric and micrometric scale of surface roughness) depending on the applied processes in plasma conditions (deposition on DLC:N and or DLC:Si layers in various configurations). Presumably, PU implants and scaffolds with the proposed coatings will be more resistant to degradation. Moreover, the resulting surface modification with roughness in nanometric scale enhanced the adhesion of eukaryotic cells enabling proper osseointegration and probably will be more beneficial for inhibition of bacteria adhesion and development of serious infections. None of the obtained modifications exhibited significant cytotoxic activity against the MG-63 and HaCat cell lines in vitro, thus the resulting DLC:Si structures presumably will promote the processes of bio-integration.

Acknowledgements This work was supported by the statutory research of the Department of Physical Chemistry and Modeling of the Faculty of Materials Science and Ceramics AGH (Subject Number
11.11.160.768). The authors also thank Agnieszka Kyzioł, Ph.D., for carrying out the biological tests.

Open Access This article is licensed under a Creative Commons Attribution 4.0 International License, which permits use, sharing, adaptation, distribution and reproduction in any medium or format, as long as you give appropriate credit to the original author(s) and the source, provide a link to the Creative Commons licence, and indicate if changes were made. The images or other third party material in this article are included in the article's Creative Commons licence, unless indicated otherwise in a credit line to the material. If material is not included in the article's Creative Commons licence and your intended use is not permitted by statutory regulation or exceeds the permitted use, you will need to obtain permission directly from the copyright holder. To view a copy of this licence, visit http://creativecommons.org/licenses/by/4.0/.

\section{References}

1. K. Kyzioł, Ł. Kaczmarek, A. Kyzioł, Surface functionalization of biomaterials. in: V.K. Thakur, M.K. Thakur, M.R. Kessler (Eds.), Handbook of Composite from Renewable Materials, Wiley-Scrivener, pp. 457-490 (2017). https://doi.org/10.1016/ B978-0-12-397157-9.00016-3.

2. G. Wu, M. Zhou, Y. Ke, Polyurethane tethering natural antibacterial substances for catheter applications. Mater. Lett. 223, 239-242 (2018). https://doi.org/10.1016/j.matlet.2018.04.051

3. Z. Ma, Z. Mao, C. Gao, Surface modification and property analysis of biomedical polymers used for tissue engineering. Colloid. Surface. B. 60, 137-157 (2007). https://doi.org/10.1016/j.colsu rfb.2007.06.019

4. L. Minati, C. Migliaresi, L. Lunelli, G. Viero, M. Dalla Serra, G. Speranza, Plasma assisted surface treatments of biomaterials. Biophys. Chem. 229, 151-164 (2017). https://doi.org/10.1016/j. bpc.2017.07.003.

5. R. Matsumoto, K. Sato, K. Ozeki, K. Hirakuri, Y. Fukui, Cytotoxicity and tribological property of DLC films deposited on polymeric materials. Diam. Relat. Mater. 17, 1680-1684 (2008). https ://doi.org/10.1016/j.diamond.2008.02.027

6. J.F. Friedrich, P. Rohrer, W. Saur, T. Gross, A. Lippitz, W. Unger, Improvement in polymer adhesivity by low and normal pressure plasma surface modification. Surf. Coat. Technol. 59, 371-378 (1993). https://doi.org/10.1016/0257-8972(93)90115-5

7. F. Mwale, H.T. Wang, V. Nelea, L. Luo, J. Antoniou, M.R. Wertheimer, The effect of glow discharge plasma surface modification of polymers on the osteogenic differentiation of committed human mesenchymal stem cells. Biomaterials 27, 2258-2264 (2006). https://doi.org/10.1016/j.biomaterials.2005.11.006

8. A. Ohl, K. Schröder, Plasma-induced chemical micropatterning for cell culturing applications: a brief review. Surf. Coat. Technol. 116-119, 820-830 (1999). https://doi.org/10.1016/S0257 $-8972(99) 00150-4$

9. C. Oehr, Plasma surface modification of polymers for biomedical use. Nucl. Instruments. Methods. Phys. Res. Sect. B. Beam. Interact. with Mater. Atoms. 208, 40-47 (2003). https://doi. org/10.1016/S0168-583X(03)00650-5.

10. L. Martinu, O. Zabeida, J.E. Klemberg-Sapieha, Handbook of Deposition Technologies for Films and Coatings, 3rd edn (Elsevier, Amsterdam, 2010), pp. 394-467. https://doi.org/10.1016/ B978-0-8155-2031-3.00009-0.

11. H. Yasuda, Modification of polymers by plasma treatment and by plasma polymerization. Radiat. Phys. Chem. 9, 805-817 (1977). https://doi.org/10.1016/0146-5724(77)90192-3 
12. J.S. Hsu, S.S. Tzeng, Y.J. Wu, Influence of hydrogen on the mechanical properties and microstructure of DLC films synthesized by r.f.-PECVD, Vacuum. 83, 622-624 (2008). https://doi. org/10.1016/j.vacuum.2008.04.070.

13. J. Vetter, 60years of DLC coatings: Historical highlights and technical review of cathodic arc processes to synthesize various DLC types, and their evolution for industrial applications. Surf. Coat. Technol. 257, 213-240 (2014). https://doi.org/10.1016/j.surfc oat.2014.08.017

14. D. Martinez-Martinez, J.T.M. De Hosson, On the deposition and properties of DLC protective coatings on elastomers: a critical review. Surf. Coat. Technol. 258, 677-690 (2014). https://doi. org/10.1016/j.surfcoat.2014.08.016

15. T. Nakahigashi, Y. Tanaka, K. Miyake, H. Oohara, Properties of flexible DLC film deposited by amplitude-modulated RF P-CVD. Tribol. Int. 37, 907-912 (2004). https://doi. org/10.1016/j.triboint.2004.07.007

16. J.M. Lackner, R. Major, L. Major, T. Schöberl, W. Waldhauser, RF deposition of soft hydrogenated amorphous carbon coatings for adhesive interfaces on highly elastic polymer materials. Surf. Coat. Technol. 203, 2243-2248 (2009). https://doi. org/10.1016/j.surfcoat.2009.02.012

17. A. Tomita, M. Kusuda, S. Otsuki, Y. Oka, Y. Nishimura, A. Murakami, M. Yatsuzuka, Enhancement of adhesive strength of DLC film prepared by PBIID on Co-Cr alloy for biomaterial. Thin Solid Films 506-507, 59-62 (2006). https://doi. org/10.1016/j.tsf.2005.08.073

18. J. Robertson, Diamond-like amorphous carbon. Mater. Sci. Eng. R Rep. 37, 129-281 (2002). https://doi.org/10.1016/S0927 -796X(02)00005-0

19. D.W. Ren, Q. Zhao, A. Bendavid, Surface \& coatings technology anti-bacterial property of Si and F doped diamond-like carbon coatings. Surf. Coat. Technol. 226, 1-6 (2013). https://doi. org/10.1016/j.surfcoat.2013.03.025

20. L. Swiatek, A. Olejnik, J. Grabarczyk, A. Jedrzejczak, A. Sobczyk-Guzenda, M. Kaminska, W. Jakubowski, W. Szymanski, D. Bociaga, Multi-doped diamond like-carbon coatings (DLC-Si/ $\mathrm{Ag}$ ) for biomedical applications fabricated using the modified chemical vapour deposition method. Diam. Relat. Mater. 67, 54-62 (2016). https://doi.org/10.1016/j.diamond.2016.03.005

21. R. Hauert, K. Thorwarth, G. Thorwarth, An overview on diamond-like carbon coatings in medical applications. Surf. Coat. Technol. 233, 119-130 (2013). https://doi.org/10.1016/j.surfc oat.2013.04.015

22. S.C. Ray, W.F. Pong, P. Papakonstantinou, Iron, nitrogen and silicon doped diamond like carbon (DLC) thin films: a comparative study. Thin Solid Films 610, 42-47 (2016). https://doi. org/10.1016/j.tsf.2016.04.048

23. M. Ban, T. Hasegawa, Internal stress reduction by incorporation of silicon in diamond-like carbon films. Surf. Coat. Technol. 162, 1-5 (2003). https://doi.org/10.1016/S0257-8972(02)00572 $-8$

24. I.A. Morozov, A.S. Kamenetskikh, M.G. Scherban, R.I. Izumov, D.M. Kiselkov, Growth of islet carbon coating on nitrogen-activated polyurethane surface. Appl. Surf. Sci. 497, 143706 (2019). https://doi.org/10.1016/j.apsusc.2019.143706

25. O. Sharifahmadian, F. Mahboubi, A. Oskouie, Structural evolution and tribological behavior of nitrogen-doped DLC coatings deposited by pulsed DC PACVD method. Diam. Relat. Mater. 91, 74-83 (2019). https://doi.org/10.1016/j.diamond.2018.11.004

26. P. Alves, R. Cardoso, T.R. Correia, B.P. Antunes, I.J. Correia, P. Ferreira, Surface modification of polyurethane films by plasma and ultraviolet light to improve haemocompatibility for artificial heart valves. Colloid. Surface. B. 113, 25-32 (2014). https://doi. org/10.1016/j.colsurfb.2013.08.039
27. K. Kyzioł, J. Oczkowska, D. Kottfer, M. Klich, Ł. Kaczmarek, A. Kyzioł, Z. Grzesik, Physicochemical and biological activity analysis of low-density polyethylene substrate modified by multilayer coatings based on DLC structures, obtained using RF CVD method. Coatings. 8(135), 135 (2018). https://doi.org/10.3390/ coatings 8040135

28. L. Körner, A. Sonnenfeld, P.R. Von Rohr, Multilayer diffusion barrier coatings on poly(propylene) with improved temperature durability. Plasma Process. Polym. 6, 660-664 (2009). https://doi. org/10.1002/ppap.200931705

29. T.F. Zhang, J.J. Pu, Q.X. Xia, M.J. Son, K.H. Kim, Microstructure and nano-wear property of Si-doped diamond-like carbon films deposited by a hybrid sputtering system. Mater. Today Proc. 3, S190-S196 (2016). https://doi.org/10.1016/j.matpr.2016.02.032

30. G. Leal, M.A. Fraga, L.A. Rasia, M. Massi, Impact of high N 2 flow ratio on the chemical and morphological characteristics of sputtered N-DLC films. Surf. Interface Anal. 49, 99-106 (2016). https://doi.org/10.1002/sia.6064

31. Z. Novotná, S. Rimpelová, P. Ju, M. Veselý, Z. Kolská, Š. Václav, The interplay of plasma treatment and gold coating and ultrahigh molecular weight polyethylene: on the cytocompatibility. Mater. Sci. Eng. C. 71, 125-131 (2017). https://doi.org/10.1016/j. msec.2016.09.057

32. D.D. Batory, A. Jedrzejczak, W. Szymanski, P. Niedzielski, M. Fijalkowski, P. Louda, I. Kotela, M. Hromadka, J. Musil, Mechanical characterization of a-C:H:SiOx coatings synthesized using radio-frequency plasma-assisted chemical vapor deposition method. Thin Solid Films 590, 299-305 (2015). https://doi. org/10.1016/j.tsf.2015.08.017

33. S.-E. Ong, S. Zhang, H. Du, D. Sun, Relationship between bonding structure and mechanical properties of amorphous carbon containing silicon. Diam. Relat. Mater. 16, 1628-1635 (2007). https://doi.org/10.1016/j.diamond.2007.02.009

34. T. Zhou, Y. Zhu, X. Li, X. Liu, K.W.K. Yeung, S. Wu, X. Wang, Z. Cui, X. Yang, P.K. Chu, Surface functionalization of biomaterials by radical polymerization. Prog. Mater. Sci. 83, 191-235 (2016). https://doi.org/10.1016/j.pmatsci.2016.04.005

35. A. Kyzioł, K. Kyzioł, Surface Functionalization With Biopolymers via Plasma-Assisted Surface Grafting and Plasma-Induced Graft Polymerization-Materials for Biomedical Applications, Biopolymer Grafting. (Elsevier, 2018) pp. 115-151. https://doi. org/10.1016/B978-0-12-810462-0.00004-1.

36. T. Iseki, H. Mori, H. Hasegawa, H. Tachikawa, K. Nakanishi, Structural analysis of Si-containing diamond-like carbon. Diam. Relat. Mater. 15, 1004-1010 (2006). https://doi.org/10.1016/j. diamond.2005.12.020

37. Z. Chen, H. Lin, J. Zhou, Z. Ma, E. Xie, IR studies of SiCN films deposited by RF sputtering method. J. Alloys Compd. 487, 531-536 (2009). https://doi.org/10.1016/j.jallcom.2009.08.009

38. W. Kafrouni, V. Rouessac, A. Julbe, J. Durand, Synthesis of PECVD a-SiC X N Y : H membranes as molecular sieves for small gas separation. J. Membr. Sci. 329, 130-137 (2009). https ://doi.org/10.1016/j.memsci.2008.12.028

39. E. Vassallo, A. Cremona, F. Ghezzi, F. Dellera, L. Laguardia, G. Ambrosone, U. Coscia, Structural and optical properties of amorphous hydrogenated silicon carbonitride films produced by PECVD. Appl. Surf. Sci. 252, 7993-8000 (2006). https://doi. org/10.1016/j.apsusc.2005.10.017

40. A. Varma, V. Palshin, E.I. Meletis, Structure - property relationship of Si-DLC films. Surf. Coat. Technol. 148, 305-314 (2001). https://doi.org/10.1016/S0257-8972(01)01350-0

41. F. Giorgis, C.F. Pirri, E. Tresso, Structural properties of a-Si1$\mathrm{xNx}$ : $\mathrm{H}$ films grown by plasma enhanced chemical vapour deposition by $\mathrm{SiH}_{4}+\mathrm{NH}_{3}+\mathrm{H}_{2}$ gas mixtures. Thin Solid Films 307, 298-305 (1997). https://doi.org/10.1016/S0040-6090(97)00272-1 
42. J.L. Lanigan, C. Wang, A. Morina, A. Neville, Repressing oxidative wear within Si doped DLCs. Tribol. Int. 93, 651-659 (2016). https://doi.org/10.1016/j.triboint.2014.11.004

43. S. Jonas, M. Januś, J. Jaglarz, K. Kyzioł, Formation of $\operatorname{SixNy}(\mathrm{H})$ and $\mathrm{C}: \mathrm{N}: \mathrm{H}$ layers by plasma-assisted chemical vapor deposition method. Thin Solid Films 600, 162-168 (2016). https://doi. org/10.1016/j.tsf.2016.01.016

44. T. Szörényi, C. Fuchs, E. Fogarassy, J. Hommet, F. Le Normand, Chemical analysis of pulsed laser deposited a-CNx films by comparative infrared and X-ray photoelectron spectroscopies. Surf. Coat. Technol. 125, 308-312 (2000). https://doi.org/10.1016/ S0257-8972(99)00580-0

45. P. Slepička, N. Kasálková Slepičková, J. Siegel, Z. Kolská, L. Bačáková, V. Švorčík, Nano-structured and functionalized surfaces for cytocompatibility improvement and bactericidal action. Biotechnol. Adv. 33, 1120-1129 (2015). https://doi.org/10.1016/j. biotechadv.2015.01.002.

46. X. Zhang, L. Wang, E. Levänen, Superhydrophobic surfaces for the reduction of bacterial adhesion. RSC Adv. 3, 12003-12020 (2013). https://doi.org/10.1039/c3ra40497h
47. M.H. Ahmed, J.A. Byrne, W. Ahmed, Characteristic of silicon doped diamond like carbon thin films on surface properties and human serum albumin adsorption. Diam. Relat. Mater. 55, 108116 (2015). https://doi.org/10.1016/j.diamond.2015.03.016

48. A.A. Ogwu, T.I.T. Okpalugo, N. Ali, P.D. Maguire, J.A.D. McLaughlin, Endothelial cell growth on silicon modified hydrogenated amorphous carbon thin films. J. Biomed. Mater. Res. B. 85B, 105-113 (2008). https://doi.org/10.1002/jbm.b.30922

49. K. Kyzioł, Ł. Kaczmarek, G. Brzezinka, A. Kyzioł, Structure, characterization and cyto toxicity study on plasma surface modified Ti-6Al-4V and $\gamma$-TiAl alloys. Chem. Eng. J. 240, 516-526 (2014). https://doi.org/10.1016/j.cej.2013.10.091

Publisher's Note Springer Nature remains neutral with regard to jurisdictional claims in published maps and institutional affiliations. 